\title{
ESTATÍSTICAS EDUCACIONAIS COMO UM SISTEMA DE RAZÃO: RELAÇÕ ES ENTRE GOVERNO DA EDUCAÇÃO E INCLUSÃO E EXCLUSÃO SOCIAIS*
}

\author{
TOM POPKEWITZ** \\ SVERKER LINDBLAD ***
}

\begin{abstract}
RESU M 0 : 0 ensaio começa por examinar as estatísticas nacionais e internacionais como campo de produção e reprodução culturais preocupado com a administração social da liberdade do indivíduo. Esta administração social apresenta duasfacetas, pois, ao tornar o mundo inteligível e calculável para intervenções políticas e sociais, ela acarreta um efeito secundário. D e fato, a administração social permitenão apenas realizar intervenções imediatas ou futuras nas vidas de seres humanos individuais, como também faz com queas mudanças nas condições das pessoas produzam alterações no tipo de pessoas que são. N esta última perspectiva, os relatórios estatísticos nacionais e internacionais de estatísticas educacionais são enfocados como fabricações de categorias de pessoas. Fabricações quelevam a considerar o conhecimento estatístico como uma ficção, no sentido de que suas categorias não passam de representações elaboradas para identificar e ordenar relações, visando um planejamento social, como acontece com classificações como emprego/desemprego, 'de risco', etnicidade e minorias. Ademais, essas fabricações também constróem biografias ligadas a ações individuais e participação. Este ensaio examina: (1) O sargumentos contemporâneos que enfocam as estatísticas como uma função de resolução de problemas do Estado moderno. (2) As estatísticas são então consideradas historicamente como integrando regras e padrões de razão particulares ligados à administração pelo Estado de populações em nome da liberdade. Tal administração envolve a 'contenção do acaso' ao tornar os objetos do mundo inteligíveis e calculáveis para as políticas. (3) A terceira seção busca mostrar como as categorias e grandezas de números constróem uma causali dade prática de desvio ligada aos ti pos de pessoas ebiografias
\end{abstract}

* Q uero agradecer a M arianne Bloch, M irian D avid, Ruth Gustafson, Kenneth H ultqvist, $\mathrm{N}$ oah Sobe e os integrantes do meu seminário sobre paradigmas de pesquisa por seus comentários sobre as versões anteriores.

Traduzido da língua inglesa por Alain François, com revisão técnica de M irian Warde.

* University of W isconsin (M adison, USA). E-mail: tspopkew@facstaff.wisc.edu

*** Uppsala University, D epartment of Pedagogy (Sweden). E-mail: sverker.lindblad@ped.uu.se 
sobre os quais os planejadores sociais devem agir. (4) Finalmente, a noção de 'de risco', encontrada em relatórios políticos e estatísticos recentes, é explorada como integrando um conjunto particular de regras de raciocínio produtoras de biografias que incluem e excluem ao mesmo tempo. A finalidade da nossa investigação, entretanto, é outra: trata de examinar o sistema de razão no qual circulam os discursos estatísticos e de tornar aparente a dualidade do conhecimento sobre educação no governo da inclusão/excl usão sociais. As regras utilizadas para ampliar a inclusão são, ao mesmo tempo, regras de normalidade e divisões, que implicam a construção de sistemas que tanto excluem como incluem.

Palavras chave: Sistemas de Razão; Estatísticas; Governo Educacional; Exclusão; Inclusão; Política; M udanças.

Introdução

$\mathrm{N}$ este artigo, examinamos relatórios nacionais e internacionais de estatísticas educacionais como discursos que fabricam, no duplo sentido da palavra inglesa de ficção e 'construção'. O conhecimento da estatística é uma ficção, pois as categorias não são reais, mas representações elaboradas para identificar e ordenar relações e permitir planejamentos sociais, como mostra a história de classificações como emprego/ desemprego, 'de risco' e socialmente desfavorecido. Essa noção de números enquanto ficções não deixa de reconhecer que os números respondem a algo no mundo que chamou nossa atenção. Além do mais, as ficções têm um efeito prático ao 'construir' que tipo e quanto de atenção se deve dar a fenômenos sociais. Embora não sem contestações, as categorias e grandezas estatísticas entremeiam-se a outros discursos para formar um sistema de razão que rege, como argumentaremos neste artigo, a maneira segundo a qual constituem-se problemas sobre os quais se deve agir e ordena os objetos e características das pessoas sobre as quais se deve agir, as relações por meio das quais causas são determinadas e problemas remediados e os caminhos para as próprias possibilidades de mudança. A palavra estatística, portanto, nesta discussão, não se refere a números instituídos em projetos políticos e cujos erros devem ser corrigidos por melhores fórmulas estatísticas ou aplicações mais corretas.

Contudo, o assunto de nossa pesquisa não se limita à maneira segundo a qual os números ordenam e disciplinam o que se vê e sobre 0 qual se pensa e age. As formulações de relatórios estatísticos evoluem num campo desigual. As normas embutidas nas categorias sociais, econômicas e escolares que constróem classes de pessoas (de realização ou de 
"amor-próprio" da criança) funcionam para desqualificar certas crianças que não "se encaixam" nas normas da média, feitas para parecer universais, mas compostas a partir de uma localização e de disposições e gostos históricos particulares (Bourdieu, 1979/1984). Construídas para buscar uma sociedade mais inclusiva, as categorias e divisões das comparações estatísticas nacionais e internacionais de educação, como argumentaremos, contêm sua própria ironia. A conjunção da política e da pesquisa rumo ao que a literatura chama de 'inclusão' acaba produzindo, de modo irônico, certas categorias de exclusão junto às de inclusão (Popkewitz \& Lindblad, 2000).

Esse interesse por estatísticas escolares como prática de governo surgiu de uma pesquisa comparativa que abrangeu sete países europeus (abreviada em EGSIE). ${ }^{1}$ Esse estudo focaliza as relações entre governança educacional e exclusão social. N ele, a equipe de pesquisa examinou como as estatísticas foram utilizadas na política e nas práticas. Esse exame de textos políticos e as entrevistas com elaboradores de políticas ou atores do sistema educacional e professores em escolas locais, revela que as estatísticas serviram de referência constante para definir problemas educacionais e programas de reformas. ${ }^{2}$ Esses diferentes estudos nacionais foram integrados neste ensaio.

0 artigo começa por examinar alguns argumentos contemporâneos sobre estatísticas enquanto função de administração no estado moderno. Argumentamos que esta maneira de colocar o problema comporta certas dificuldades, uma vez que as estatísticas são tratadas apenas como um discurso cuja única lógica éa dos números introduzidos nos planejamentos do Estado. N osso argumento é diferente e contrário à intuição. D esenvolvemos, na segunda seção, a idéia de estatística como campo de produção e reprodução culturais preocupado com a administração social da liberdade do indivíduo. Essa administração deve tornar o mundo inteligível e calculável para as intervenções políticas e sociais. Entretanto, essas intervenções envolvem mais incertezas do que certezas e, portanto, apelam para o raciocínio de probabilidade no intuito de "conter o acaso" e, assim, possibilitar o planejamento social (H acking, 1990). N a terceira seção, examinamos como os limites e as características internas dos espaços de populações, economia, sociedade e escolaridade tornam-se não apenas inteligíveis, calculáveis e praticáveis "mediante representações que são em parte numéricas, como também avaliáveis, uma vez que as percentagens, tabelas, gráficos, tendências e comparações numéricas são essenciais ao exame minucioso e crítico por parte da autoridade numa sociedade" (Rose, 1999, p. 197). M ais particularmente, consideramos 
como diferentes grandezas de números são aproximadas entre si para produzir uma causalidade prática sobre a qual os especialistas possam agir: a construção de classes de pessoas e de biografias mediante práticas institucionais (ver tabela 1.) A importância da construção de classes de pessoas e de biografias, prosseguimos, é que as diferenças estabelecidas para encontrar caminhos rumo a uma inclusão maior são também divisões e distinções que excluem, embora de maneira diferente das estabelecidas em estudos organizacionais e políticos formais. Finalmente, retomamos, na quarta seção, a noção de de risco encontrada em relatórios políticos e estatísticos recentes, para investigar como a categoria de inclusão fabrica, no duplo sentido de ficção e construção, biografias que tanto excluem como incluem.

N ossos argumentos sobre estatísticas de educação, portanto, nada têm a ver com as noções de "bom/ruim," de utilidade ou de erros; também não buscam censurar ou condenar os números ou estatísticas sobre educação. N ossa tarefa de investigação é diferente: examinar 0 sistema de razão em que os discursos estatísticos circulam e formam uma relação entre governar e inclusão/exclusão sociais. Buscamos tornar aparente a dualidade dos conheci mentos sobre educação. As regras visando a ampliar a inclusão são também regras de normalidade e divisões e, portanto, implicam a construção de sistemas que excluem tanto quanto incluem. Tomar os conhecimentos sobre política e educação como uma problemática de estudo é perturbar "aquilo que forma as fundações do presente para torná-lo mais uma vez estranho e nos levar a nos perguntar como conseguiu parecer tão natural" (Rose, 1999, p. 58). Mostrar a natureza contingente dos arranjos com os quais convivemos é revelar o papel desempenhado por hábitos para manter esses arranjos unidos e contestar as estratégias que regem as possibilidades humanas.

\section{A função prática das estatísticas educacionais na governança moderna}

As estatísticas participam da lógica sedutora da ciência numa idade de racionalidade e razão. Como a pesquisa EGSIE considera a relação entre governança educacional e inclusão e exclusão sociais, os indicadores nacionais e internacionais centrais sobre o progresso educacional ligado à inclusão social são estatísticas. A informação aparece como dados que convidam a comparações entre categorias no tempo e no espaço e podem ser utilizados em vários tipos de análises quantitativas, mais particularmente quando a pesquisa lida com política educacional. $\mathrm{N}$ a tabela 1 , as 
categorias 'homens', 'mulheres', e 'grupo de pouco êxito' são apresentadas e comparadas entre si e em relação à categoria 'total'. As linhas apresentam uma combinação de casos nacionais (da Austrália ao Reino U nido) e as colunas, um conjunto de categorias (baixo êxito educacional, i.e., apenas ensino médio inferior).

Tabela 1

Percentagem de pessoas entre 20 e 24 anos cujo maior êxito educacional não passa do ensino médio inferior: 1995

\begin{tabular}{lcccc}
\hline Casos N acionais & $\begin{array}{c}\text { T otal } \\
1995\end{array}$ & $\begin{array}{c}\text { H omens } \\
1995\end{array}$ & $\begin{array}{c}\text { M ulheres } \\
1995\end{array}$ & $\begin{array}{c}\text { Percentagem de desempregados no } \\
\text { grupo de baixo êxito educacional }\end{array}$ \\
\hline Austrália & 32 & 28 & 36 & 13 \\
Finlândia & 21 & 21 & 21 & 24 \\
Grécia & 26 & 31 & 22 & 13 \\
Portugal & 57 & 64 & 49 & 11 \\
Espanha & 41 & 46 & 35 & 31 \\
Suécia & 12 & 11 & 13 & 20 \\
Reino U nido & 11 & 11 & 11 & 21 \\
\hline
\end{tabular}

Fonte: OCDE, Análise de política educacional, anexo estatístico, p. 78.

M ediante essas estatísticas educacionais, tanto as ambições educacionais como as análises de educação são constituídas por tabelas e comparações de números. A tabela nos confere possibilidades de comparar tanto os diferentes casos nacionais como as questões de gênero por meio da estrutura de relações nela inscrita. Segundo a tabela, Portugal pode ser identificado como um caso que desvia muito dos da Suécia e do Reino U nido, com uma proporção bem maior de pessoas que não passaram do ensino médio inferior. $\mathrm{Na}$ tabela, o baixo êxito escolar e 0 desemprego estão também ligados entre si, revelando um nível de desemprego alto entre os que tiveram baixo sucesso escolar, o que deixa a entender que mais educação recompensa os indivíduos.

Com as informações ao longo do tempo, os números fornecem uma maneira de raciocinar a respeito da relação entre fenômenos sociais e educacionais. O s números definem trajetórias para sinalizar progressos ou identificar locais potenciais de intervenção por meio de políticas de estado. ${ }^{3}$ O s números realçam normas e marcam diferenças nos graus de desvio quando se analisam as variâncias de padrão em nossos dados. 
Além disso, ferramentas como as análises de conjuntos oferecem aos elaboradores de políticas e aos pesquisadores oportunidades para criar novas categorias que emergem dos padrões de dados.

C ontudo, os números na tabela não são apenas descrições de divisões e relações sociais a partir das quais se pode raciocinar a respeito dos problemas educacionais. A estatística é uma modalidade chave para a produção de conhecimento necessário para governar. Foucault (1988) argumenta que governar tem envolvido, pelo menos desde o século XVIII, uma correlação constante entre uma individual ização crescente e a construção de uma totalidade que permite que nos reconheçamos como pertencendo a uma sociedade, como parte de uma entidade social, parte de um Estado-nação. Q uando as pessoas falavam da polícia, argumenta Foucault (1979), faziam referência às técnicas específicas por meio das quais um governo no quadro do Estado conseguia governar de modo a que indivíduos pudessem ser 'cidadãos' produtivos. O s teóricos alemães da polícia vincularam uma ciência política de administração calculada da população (statistik) com os fins de riqueza, de ordem pública, de virtude e de felicidade. Por volta do século XIX, a estatística conceituava as necessidades humanas em termos instrumentais e empíricos para 0 funcionamento do Estado. Seu sistema de classificação social não se limitava a classificar, mas servia de forma institucional para estabelecer bases para a autoridade e a legitimidade por meio das categorias que especificavam, na medida em que pareciam tanto naturais quanto socialmente reais (Verdery, 1993, p. 37).

Em termos de representação, a relevância das estatísticas é tão grande que suas formulações vêm à tona não apenas em declarações políticas nacionais e nas entrevistas realizadas com atores políticos e do sistema educacional, como em diferentes correntes ideológicas de críticas à educação nos países contemplados pelo estudo EGSIE. Entretanto, não é apenas um discurso de Europeus; se olharmos para as reformas atuais nos Estados U nidos, por exemplo, os resultados estatísticos providenciam um princípio organizador maior na enunciação do problema das mudanças educacionais e da natureza das reformas. É a linguagem que atravessa as declarações do Estado, dos profissionais e das fundações sobre os professores e suas práticas educacionais. 0 relatório do American Council on Education (Conselho Americano sobre Educação - 1999) a respeito da formação dos professores, por exemplo, define o problema em termos oriundos das diferentes medidas estatísticas. A maior parte da seção Resultados (Findings) do relatório serve para argumentar que testes de realização 'mostram' que o professor é singular, "nada é mais 
poderoso, para influenciar os ganhos de realização dos alunos, que a qualidade do professor" (American Council on Education, 1999, p. 3). Em outros pontos, percentagens de Estados usando padrões para preparar à tecnologia são utilizados para indicar a necessidade de mudança. $\mathrm{A}$ National Commission on Teaching ( Comissão Nacional sobre Ensino) e a America's Future (Futuro da América - 1996) também definem o problema das mudanças em relação a números: números de professores não licenciados, números de professores ensinando na área de licença, percentagem de variância entre realização e experiência do professor, e assim por diante.

Portanto, começamos nossa discussão sobre estatísticas com uma observação a respeito das funções práticas dos números. ${ }^{4} \mathrm{~A}$ produção de estatísticas oficiais é, hoje, "um empreendimento rotineiro que tem uma ampla infra-estrutura em programas de estados e de universidade cuja escala e sofisticação se estende a campos mais vastos da vida social e que se infiltra profundamente no funcionamento da sociedade" (Starr, 1987, p. 23). A própria fé nas estatísticas está ligada a seu potencial para governar o funcionamento de governos democráticos em nível tanto estadual ou interestadual como global. Considera-se que oferecem uma distribuição da representação, por examinar as reivindicações de legislação em conflito e por sua receptividade a diversos grupos de interesses. Portanto, as estatísticas oferecem uma liga de uniformidade e confiança em torno do qual os objetos são contados, o que possibilita que ordens de magnitude não afins sejam relacionadas entre si para estabilizar o que está em fluxo. $\mathrm{N}$ as democracias, as estatísticas são vistas como uma tecnologia que diminui o medo de poder irrestrito e contribui à liberdade ao manter uma regra de lei impessoal, uma redução da complexidade e classificações meramente técnicas para aplicar os princípios democráticos de eqüidade e justiça, de modo a considerar a pobreza ou a integração social e econômica (Alonso \& Starr, 1987).

$\mathrm{N}$ a modernidade, a mágica das estatísticas enquanto tecnologia de governança não ocorre sem hesitações nem reflexividade. $\mathrm{N}$ as contribuições das estatísticas para a política e a ciência modernas, há um reconhecimento de que os números não são simples espelhos da realidade, mas refletem pressupostos e teorias sobre a natureza da sociedade. As estatísticas intervêm nos processos de governo, uma vez que os números moldam nossa maneira de 'ver' as possibilidades de ação, de inovação e até nossa 'visão' de nos mesmos. São produtos de interesses sociais, políticos e econômicos, sensíveis às decisões metodológicas de organizações complexas com verbas limitadas. Além do mais, os números refletem 0 
passado, uma vez que "ecoam seu passado assim como a superfície de uma paisagem reflete sua geografia subjacente." (Alonso \& Starr, 1987, p. 1). Essa função recursiva é mais evidente na medida em que as estatísticas formam uma determinação importante da política social, como estabelecer para onde o dinheiro vai e os limites das categorias para definir os problemas políticos e organizar 'fatos' que permitam chegar a soluções.

Embora reconheçamos a função recursiva das estatísticas, estas estabelecem também uma relação entre poder e conhecimento. Kal pagam (2000) argumenta, por exemplo, que os conhecimentos estatísticos possibilitam conceber a economia e a sociedade como modos de intervenção. As populações emergiram como um dado, ou campo de intervenção, e como um objeto de técnicas governamentais. Ao focalizar os discursos administrativos de governança colonial, ele argumenta que organizar as pessoas em populações por meio da coleta de estatísticas não serviu apenas para fornecer representações que permitissem certos tipos de intervenções, mas que a organização epistemológica das pessoas em populações estatísticas integrou as categorias ocidentais de espaço, tempo, medida, razão e causalidade, que constituíram as ciências modernas e não faziam parte, previamente, do tecido 'mental' dessas sociedades. D iferentemente do conhecimento etnográfico que busca apresentar a 'alteridade' em sua unicidade, o conhecimento estatístico transforma a 'alteridade' em diferenças que se tornam comparáveis e mensuráveis. Com isso, as estatísticas comparativas tornam-se cada vez mais uma ferramenta que torna comensuráveis os diversos arranjos sociais e modos de vida, um aspecto importante das entidades internacionais contemporâneas que produzem relatórios sobre o 'progresso' educacional entre nações.

\section{Juntando os registros de administração social eliberdade: razão por meio das estatísticas}

N esta seção, mostraremos como os números permitem um planejamento administrativo à medida que fenômenos aparentemente disparatos e incomensuráveis são transformados em 'coisas' mensuráveis que são comensuráveis e comparáveis. N osso argumento é que essa administração acarreta a contenção do acaso por meio das teorias de probabilidade. A meta dessa administração é a de conseguir não apenas intervenções imediatas ou futuras nas vidas de seres humanos individuais, como também que as mudanças nas condições das pessoas produzam mudanças no 
tipo de pessoas que elas são (H acking, 1995, p. 351). Além do mais, os números não são meros números, mas circulam num campo de produção e reprodução cultural.

\subsection{Conter o acaso e construir um objeto de administração social}

A importância das comparações internacionais por meio das estatísticas é um fenômeno que data de depois da Segunda Guerra M undial. Elas visam construir uma fonte comparativa de dados a respeito da interação aparente de sociedades diversificadas; e uma Estatística comparativa que tem 'traduzibilidade' torna mensuráveis os diversos arranjos sociais e modos de vida. As categorias dos relatórios internacionais sobre desempenho educacional costumam se refletir nos exames nacionais de progresso educacional e nas políticas para modernizar o sistema educacional. ${ }^{5}$

Education at a glance, OECD Indicators (1998 - Educação: um apanhado geral, Indicadores da OCDE) é um desses relatórios que tem importância para os planejadores educacionais na Europa, uma vez que consideram a política do Estado ligada à educação e, embora de modo menos óbvio, nos EUA. O documento da O rganização de Cooperação e D esenvolvimento Econômicos (OCDE) é patrocinado pelos maiores países industrializados e destinado à coordenação internacional e à administração social de nações. A magnitude das categorias deve conferir inteligibilidade às diferenciações de escolaridade relacionadas a fatores sociais e econômicos.

É fácil olhar para o relatório e focalizar os elementos individuais das 'condições de educação' através das nações. Como outros relatórios, Education at a glance, OECD Indicators (1998) descreve uma visão bastante padronizada ao se concentrar sobre matrículas educacionais através de diferentes camadas, tal como (a) as matrículas escolares brutas (as matrículas totais na educação fundamental, independentemente da idade, exprimida como uma percentagem do grupo de idade da população, correspondendo às regulações nacionais para esse nível de educação; (b) a expectativa de vida escolar (o número de anos que se espera que uma criança permaneça na escola, ou universidade, anos de repetência incluídos); (c) percentagem de repetentes (número total de alunos que são matriculados na mesma série que 0 ano anterior, exprimida como percentagem das matrículas totais no ensino fundamental); (d) a proporção líquida de matrículas (as matrículas por grupo de idade correspondendo à idade escolar oficial para o nível de educação 
atual) e (e) as matrículas brutas para a educação superior (isto é, as matrículas totais independentemente da idade, exprimidas como percentagem da população no grupo dos cinco anos após a idade de fim do ensino médio).

Contudo, quando lidos de mais perto, esses relatórios de estatísticas nacionais e internacionais vinculam discursivamente educação e bem-estar econômico, justiça social, democracia e bem-estar individual. As estatísticas formam uma lógica prática de causação, por meio da qual as características salientes do desenvolvimento e da natureza progressiva dos sistemas educacionais são constituídas. ${ }^{6}$ Ao mesmo tempo, as categorias e ordens de grandeza não são meros números que relatam a condição particular de uma nação. Os números contêm o acaso por meio das tecnologias das estatísticas. Isto é, fenômenos disparatos são ordenados e tornados comensurados para a administração social. D escortina-se uma uniformidade a respeito dos objetos que são contados e ordenados. A magnitude dos números estabelece uma relação entre categorias de política - entre matrículas em diferentes níveis, os que abandonaram a escola (dropouts) e a participação de grupos socioeconômicos em diferentes níveis de êxito escolar. 0 que está em fluxo se torna estabilizado de modo a parecer apenas como um problema técnico restrito a um campo de objetividade.

A quantificação no relatório da O CDE padroniza tanto seu objeto como seu sujeito; ela padroniza o sujeito medido e 0 ato de troca não depende mais das personalidades ou do status dos envolvidos. Sua ambição é a de aumentar a eficácia dos sistemas educacionais mediante comparações centradas em um número de indicadores. Por meio de comparações educacionais numéricas constroem-se também ideais e fracassos educacionais. $M$ ais é mais e menos é menos. $E$ essas fabricações têm uma importância vital nos discursos políticos sobre educação e na identificação de crises educacionais.

\subsection{Estatísticas como campo de prática cultural}

Embora sua forma discursiva pareça concentrar-se nos aspectos técnicos da relação entre economia e educação, os textos internacionais vão mais além. Eles são um entrecruzamernto de discursos paralelos interligados que navegam pelas categorias e distinções dos números. ${ }^{7}$ 0 utro relatório internacional sobre educação da Unesco, The U nited $\mathrm{N}$ ations Economic, Scientific and Cultural O rganization (A O rganização Econômica, Científica e Cultural das N ações U nidas), por exemplo, começa assim: 
À medida queo século atual chega a seu fim, a educação vem emergindo no primeiro plano do interesse do mundo quanto a seu próprio futuro. 0 sdesafios do próximo século deeliminar a pobreza egarantir um desenvolvimento sustentável euma paz duradoura recairão sobre osjovens dehoje. Educar osjovens para enfrentar esses desafiostem se tornado um objetivo prioritário para toda sociedade. (Grifo nosso, p. 16)

0 que é percebido como uma ferramenta para capturar realidades educacionais e estabelecer distinções entre indivíduos e grupos para uma sociedade mais eqüitativa e justa, é uma in scrição que comporta diferentes discursos de educação, economia, pobreza e cultura num plano contínuo. N o plano simbólico, as estatísticas do relatório conseguem estabelecer uma racionalidade científica para exprimir as expectativas e aspirações do cidadão de diferentes nações. O s números são apresentados como uma maneira de estabelecer como combater desigual dades globais, examinando trajetórias nacionais em educação, e determinar o papel da educação enquanto motor para a necessidade de mudança.

Se tomarmos o U nesco 1998 Statistical Yearbook (1998 - Anuário Estatístico 1998 da Unesco) como exemplo de números que ilustram a relação do global com a nação, vemos que o documento foi preparado de modo a integrar dados internacionais com os coletados pelas agências nacionais de estatísticas e outros serviços. Sua meta é a de identificar graus de desenvolvimento e sua relação com as desigualdades através de áreas geográficas (p. ex., África, América Latina, Europa) e nações particulares (Tabela 2). A organização das estatísticas determina implicitamente uma noção de modernização entre nações por meio de várias tabelas, que estabelecem continuamente as magnitudes menores das populações que freqüentam as escolas em nações não industrializadas em relação a nações industrializadas. U ma das maiores categorias, por exemplo, éa de adultos iletrados, estimada e distribuída por gênero e região. As estatísticas de taxas de analfabetismo e de matrículas no ensino fundamental e médio são então relacionadas com outras grandezas, como os números de circulação de cotidianos de interesse geral e os números de aparelhos de televisão.

A hipótese de modernização embutida no número de leitores de jornais e de proprietários de televisão é adotada como indicador de desenvolvimento tanto cultural como econômico. Sendo assim, as tabelas estatísticas começam por estabelecer uma relação de causa e efeito entre alfabetismo, analfabetismo e desigualdade (gênero no relatório da U nesco). Pela maneira segundo a qual diferentes grandezas em categorias são colocadas nos documentos, essa relação não é de causação analítica, mas antes textual. 
Tabela2

\begin{tabular}{|c|c|c|c|c|c|c|c|c|}
\hline \multirow[t]{2}{*}{ Pás } & \multicolumn{2}{|c|}{$\begin{array}{l}\text { Tasesestimades } \\
\text { deandfabetismo } \\
\text { adulto pera } 1995\end{array}$} & \multicolumn{2}{|c|}{$\begin{array}{c}\text { Circulasãa de } \\
\text { cotidianospor } \\
1000 \text { habitantes }\end{array}$} & \multirow{2}{*}{$\begin{array}{c}\begin{array}{c}\text { Númarode } \\
\text { tuleisorespor } \\
1000 \text { hatitates }\end{array} \\
1996\end{array}$} & \multicolumn{3}{|c|}{ 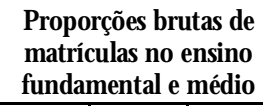 } \\
\hline & MF & M & $\mathbf{F}$ & 1996 & & MF & M & $\mathbf{F}$ \\
\hline \multicolumn{9}{|l|}{ África } \\
\hline Argália & 38.4 & 26.1 & 51.0 & 38 & 104 & 86 & 89 & 82 \\
\hline Angola & - & - & - & 12 & 27 & - & - & - \\
\hline Benin & 63.0 & 51.3 & 74.2 & 2 & 18 & 48 & 62 & 34 \\
\hline Botsuana & 30.2 & 19.5 & 40.1 & 27 & 20 & 94 & 93 & 96 \\
\hline Burkina Faso & 80.8 & 70.5 & 90.8 & 1 & 8.3 & 25 & 31 & 19 \\
\hline Burundi & 64.7 & 50.7 & 77.5 & 3 & 3.2 & 30 & 33 & 27 \\
\hline Camarões & 36.6 & 24.9 & 47.9 & 7 & 29 & - & - & - \\
\hline Cabo Verde & 28.4 & 18.6 & 36.2 & - & 3.7 & - & - & - \\
\hline $\begin{array}{l}\text { República Centro- } \\
\text { Africana }\end{array}$ & 40.0 & 31.6 & 47.6 & 2 & 4.5 & - & - & - \\
\hline Chade & 51.9 & 37.9 & 65.3 & 0.3 & 1.4 & 38 & 52 & 25 \\
\hline Comores & 42.7 & 35.8 & 49.6 & - & 1.6 & 49 & - & - \\
\hline Congo & 25.1 & 16.9 & 32.8 & - & 11.2 & 85 & 92 & 78 \\
\hline Costa do Marim & 59.9 & 50.1 & 70.0 & 16 & 62 & 48 & 57 & 38 \\
\hline
\end{tabular}

Fonte Unesco 1998 Statistical Yerrbook 
Entretanto, as categorias de números se sobrepõem às idéias para formar um campo de práticas culturais. As categorias de infância (os anos fixados para diferenciar as populações que freqüentam escolas) estão ligadas a outras categorias de modo a formar um esquema interpretativo a respeito da administração que visa a tornar uma nação mais democrática e inclusiva. D eve-se ler os dados estatísticos como vinculando a educação a práticas administrativas democráticas e calculáveis.

Contudo, como N óvoa, Alves \& Canário (no prelo) indicam num exame das estatísticas portuguesas de pobreza e êxitos e fracassos educacionais, as categorias de pobreza são características sociais que exigem atenção quanto à maneira como as estatísticas foram construídas. Em Portugal, por exemplo, a pobreza é, pelo menos, de dois tipos: um associado a áreas rurais e outro associado à pobreza urbana e dos jovens. Este último tipo de pobreza, por exemplo, diz respeito à falta de status de cidadão pleno e ao enfraquecimento dos laços sociais que têm integrado os pobres nas sociedades do sul da Europa. Além do mais, a idéia de desemprego nas tabelas estatísticas torna al gumas situações de não emprego em desemprego e deixa de lado o trabalho na economia informal, o trabalho em casa, e a inatividade involuntária de trabalhadores que foram compelidos a se aposentar.

Se retomarmos as frases assinaladas acima como 'eliminar a pobreza' e 'garantir o desenvolvimento sustentável e uma paz duradoura,' os relatórios estatísticos descritivos veiculam também um imperativo moral a respeito do progresso de sociedade. Isto é evidente, uma vez que os números internacionais circulam pelas nações para estabelecer relações práticas entre as metas coletivas da ação do estado na educação e a ordenação da própria mudança. ${ }^{8} 0$ relatório nacional da Suécia, por exemplo, vincula estatísticas de economia e organização e participação escolares a outras grandezas de diferenciação interna, como problemas gerais de contratação e retenção de professores, para estabelecer um conjunto prático de relações sobre a escolaridade, a economia e aqueles que não receberam benefícios da sociedade - os pobres, as minorias e outras classificações de excluídos (Lundahl, no prelo). Textualmente, os relatórios estatísticos devem aproximar de modo concreto as afirmações gerais de progresso das populações que precisam de administração, como as em que há divórcios, crimes infantis, pobreza ou diferenciações sociais e culturais. Estabelece-se um nexo de relações entre as características da família ou jovem em desvio e descritores de salários de professores, formação profissional e status social. As magnitudes das diferenças servem a comparar regiões mais e menos desenvolvidas, tornando-se a educação 
um lembrete através do qual se pode estabelecer um contínuo de valores que vincula economia, cultura, sociedade e educação. Lundahl (no prelo) argumenta que os indicadores estatísticos em discursos públicos suecos sobre educação e inclusão/exclusão sociais relacionam tacitamente acessibilidade, integração da população e participação enquanto maneiras de se avaliar a cidadania e democracia.

O s números reconfiguram limites sobrepostos da política, da moral, do educacional e do técnico para formar um único plano e fabricar aptidões que estão fora das normas do cidadão democrático. Alexiadou, Lawn \& Ozga (no prelo) investigam o Rowntree Foundation Report (Relatório da Fundação Rowntree, no Reino U nido, 'M onitoring Poverty and Social Exclusion' [M onitoração da Pobreza e da Exclusão Social]). O relatório identifica quarenta e seis 'indicadores-chave' de medidas sociais, culturais e econômicas que relacionam crianças e escolaridade. Existe, entre estas, um fosso entre baixa e média renda, crianças incapacitadas (que são classificadas entre os 'mais desfavorecidos' tipos de famílias na Grã-B retanha, com quase três vezes mais famílias com crianças incapacitadas no quinto mais pobre da distribuição. 0 relatório oferece distinções mais sutis quanto a que grupos precisam ser representados no problema da exclusão, diferenciando certas populações como grupos de minorias étnicas de 'Indianos, N egros, Bengaleses e Paquistaneses.'

As estratégias discursivas embutidas nesses relatórios, contudo, não são apenas simbólicas. O s números integram uma maneira de raciocinar como mentalidade de governo e tecnologia de regra. Isto se constata com facilidade se considerarmos que a categoria de 'minoria' é uma classificação que pode ser aplicada a qualquer agrupamento, segundo sua ordenação. As distinções mais sutis funcionam para separar objetivamente e classificar indivíduos ao criar diferenciações cada vez mais sutis no comportamento cotidiano (D reyfus \& Rabinow, 1983). A construção de distinções mais sutis fornece maneiras mais específicas e detalhadas de ordenar a individualidade; e no caso das estatísticas, de ordenação de populações mediante mais distinções a respeito do desvio - 0 fracasso escolar ocorre não apenas por realização, mas como abandono escolar, criança de risco, e assim por diante. As distinções mais sutis dos agrupamentos internos na escolaridade permitem calcular melhor a população sobre a qual trabalhar e permitem, assim, aumentar as possibilidades de governança de inclusão e exclusão.

Embora seja muito claro que categorias como 'minorias' são utilizadas por grupos marginalizados para conseguir serviços políticos e econômicos, essas categorias existem dentro de um sistema de razão em 
que as estatísticas não apenas estabelecem vínculos na resolução de problemas de política, mas ainda são uma prática de governo cujos métodos para resolver problemas mapeiam o que é tomado como uma inovação 'razoável', progresso, e as subjetividades de classes de pessoas. Esse último ponto é um dos focos centrais desse ensaio.

\subsection{Estatísticas como aritmética política do Estado: Práticas de governo para vincular estados e sujeitos}

Se colocarmos o panorama contemporâneo da estatística nacional e internacional num contexto histórico, ela integra uma visão oitocentista da escolaridade como um meio de 'resgatar' crianças de suas condições econômicas, sociais e culturais graças a uma intervenção planejada. A noção de resgate combina visões religiosas de sal vação com noções seculares sobre os efeitos da pobreza, da classe e discriminação social/racial (Baker, 1998; Popkewitz, 1998).

Todavia, a própria história de resgate e salvação está vinculada a mudanças expressivas na política da modernidade. Essas mudanças tinham a ver com a formação do Estado moderno. 0 problema da administração social do Estado não se limitava a cuidar de seu território, mas incluía a construção da liberdade do cidadão que participa como indivíduo que se motiva, e se torna responsivo e produtivo. A tática de reforma e a administração do bem-estar social eram parte de uma teia para vincular o Estado e seus sujeitos (Castel, 1991; H acking, 1990, 1991). ${ }^{9}$ Liberdade, autonomia individual e 'capacitação', que fluem tão livremente nas pesquisas contemporâneas e narrativas políticas, não são princípios que existem em oposição ao problema de administração social, mas que, historicamente, se constituíram mutuamente para definir a idéia de progresso.

0 agrupamento de pessoas por meio do raciocínio populacional faz tanto parte de nossa 'razão' contemporânea que costumamos não ter consciência de que os sistemas de classificação que designam as pessoas como pertencendo a uma população é uma invenção histórica e um efeito de poder. Ao aplicar um cálculo de probabilidade, o pensamento populacional constrói uma nova forma de individualidade. 0 indivíduo énormal izado em relação a agregados estatísticos a partir dos quais características específicas podem ser atribuídas ao indivíduo e de acordo com as quais uma trajetória de vida pode ser mapeada e seu desenvolvimento monitorado e supervisionado. A medição da realização escolar ligada a atributos sociais e psicológicos da criança e família produz agrupamentos de populações que relacionam, mediante tabelas estatísticas, os 'fatores' 
de êxito ou fracasso escolares. 0 raciocínio populacional normaliza por meio da construção de médias.

Graças a esse pensamento sobre raciocínio populacional podemos avançar no problema dos números como mais do que um simples meio de classificar. O s números inscrevem um sistema de ordenação e classificação que não apenas calcula e ordena racional mente grupos de pessoas, como também normaliza, individualiza e divide. Raciocinar a respeito de crianças, famílias e comunidades enquanto grupos populacionais possibilita um tipo particular de governo que coloca as características de indivíduos dentro de normas populacionais e de suas divisões.

\section{Estatísticas como teia de inteligibilidade}

N osso argumento nesse ponto é que as estatísticas não são 'meros' sistemas lógicos, mas um campo de práticas culturais que normaliza, individualiza e divide. Esse reconhecimento permite-nos concentrar a atenção sobre a 'razão' de números como a superposição de múltiplos discursos que formam uma teia, a qual confere inteligibilidade aos objetos do mundo. O s números governam, então, não como 'puros' números, mas por meio do entrecruzamernto dos discursos paralelos que circulam pelos relatórios para traçar o perfil e inventariar pessoas. ${ }^{10}$

Esta seção considera quatro pontos ligados à governabilidade produzida pelos números. Primeiro, a estatística integra uma causalidade prática que éfabricada por meio da relação de ordenação de suas categorias. Segundo, as estatísticas constróem classes de pessoas, inventários ou perfis de pessoas que podem ser geridos. Terceiro, construir classes de pessoas produz biografias que não apenas devem acompanhar os grupos, mas estabelecer a governabilidade da ação individual e da participação. Essas biografias dividem e normalizam diferentes classes de pessoas. A fabricação de classes de pessoas e biografias é uma prática de governo na construção da inclusão/exclusão.

\subsection{Estatísticas ea construção de uma causalidade prática}

As estatísticas integram um conjunto prático de causa e efeito, causalidade e uma correlação que ordena os problemas e soluções de política social. Essa causalidade não é a de uma lógica formal, mas uma

prática que se forma nos padrões de categorias, distinções e grandeza das 'relações textuais.' 
Considerar que números produzem uma causalidade prática é reconhecer que os diferentes gráficos, categorias e quantificações nos relatórios estatísticos 'constróem' um padrão de relações por meio das justaposições de categorias e distinções. 0 relatório estatístico da O CDE, Education at a glance (1998), por exemplo, oferece uma variedade de indicadores sobre educação para comparar diferentes países. 0 objetivo de Education at a glance é:

Informar o processo de formação política egarantir as responsabilidades públicas de sistemas educacionais, a O CD E busca continuamente desenvolver indicadores que possam providenciar um insight no funcionamento comparativo de sistemas educacionais focalizando os recursos humanos e financeiros investidos na educação e os retornos desses investimentos. (p. 5)

Esta causalidade prática é exprimida textualmente por meio de uma certa comunidade entre categorias que descrevem e interpretam 0 desempenho de sistemas educacionais através de relatórios nacionais e internacionais de estatísticas educacionais. ${ }^{11} 0 \mathrm{~s}$ relatórios internacionais de estatísticas educacionais, por exemplo, focalizam a relação de contextos de input e de output de educação (Lindblad, 2000). 0 contexto de input parte do princípio que os recursos para a educação produzirão coisas boas, como combater o analfabetismo ou a exclusão social, ou cidadãos competentes. As estatísticas da nação passam a ser justapostas a categorias que se circulam pelas nações como universais, devendo ser relacionados a outros Indicadores de Sistema (PN B, taxas de desemprego, expectativa de vida). 0 contexto de output focaliza o que acontece em conseqüência de dados inputs. A reestruturação da educação pode ser considerada como uma transição de um contexto de input para um contexto de output. Aqui, o foco recai sobre o uso eficiente de recursos, o queimplica definiç̧ões de quais são os outputs importantes da educação. Esses indicadores, por sua vez, são relacionados com indicadores educacionais (matrículas, percentagen s gastas em educação), proporção professor/alunos e categorias individuais (gênero, idade, etnicidade, background familiar da criança escolarizada, incapacidade física).

A magnitude das relações entre categorias estatísticas de input e output inscreve uma teia a partir da qual se confere inteligibilidade ao problema da exclusão. Esta teia se forma, por exemplo, por meio das categorias de sistema social fornecidas pelas estatísticas finlandesas, gregas, espanholas, suecas e ingl esas sobre educação. U ma série de medidas cal cula a relação entre escolaridade e inclusão social e econômica mediante essas categorias e suas quantidades (Alexiadou, no prelo; Karadjiia, no prelo; Lindblad, no prelo; Castillo Pérez, no prelo; Rinne, Kivirauma \& Simola, 
no prelo). Com tantas semelhanças entre as nações, os números sociais, estruturais e demográficos a respeito da segregação social de classes, etnicidade, raça, pobreza, rural/urbano, crime são relacionados a outros grupos populacionais de desvio, como as crianças e famílias 'de risco' que, por isso, precisam de uma assistência governamental especialmente dirigida para evitar sua exclusão. O s números desses dois conjuntos de categorias que dizem respeito a populações excluídas são então aproximados dos números dos sistemas educacionais.

$\mathrm{N}$ este sentido, os diferentes conjuntos de números estabelecem uma relação prática de grandeza, uma vez que os relatórios estatísticos fazem, textualmente, das diferentes categorias algo significativo para se pensar as causas das exclusões. Inserir crianças em espaços estatísticos significa que determinadas populações devem ser administradas e resgatadas. Renda e economia (casais sem emprego, casais pobres) são inseridas numa teia ligada à saúde (como nascimentos com baixos pesos), à estabilidade social (ambientes familiares como divórcios, divórcios em que o marido não é qualificado e 'mãe solteiras' ou filhos nascidos de adolescentes), a indicadores de desorganização social e colapsos culturais (criminais, delinqüentes juvenis, famílias sob estresse, moradores de ruas, rapazes afro-caribenhos, alunos com necessidades especiais, drogas, terror contra os colegas [bullying]). Esses indicadores são relacionados com indicadores educacionais (alunos de risco, desafeição, realização educacional, exclusão de ensino médio, faltar às aulas, elegibilidade para merendas gratuitas, falar uma língua estrangeira, inglês como segunda língua) (Alexiadou, Lawn, \& O zga, no prelo, p. 36).

Se tomarmos essas categorizações comuns à política e à pesquisa para governar a inclusão educacional esocial, existeuma ordenação contínua de uma causalidade prática sobre normalidade e desvio. A aproximação de várias distinções que são relacionadas entre si 'diz' que há al go normal do qual esses indicadores e grandezas exprimem desvios. As estatísticas produzem diferenças mediante grandezas e contínuos de valor em que 0 indivíduo é inserido. A causalidade prática das relações dos números 'diz', sem jamais falar sobre essa relação, que pobreza e exclusão econômica estão ligadas e produzidas por falta de habilidade com letras e números, mães pobres com crianças jovens, e desemprego, faltar às aulas e renovação da vizinhança.

\section{2. 'C onstruir' classes de pessoas que são governadas egovernáveis}

H acking (1995) argumenta que os números acarretam um modo de condensar ou reduzir indivíduos em formas de 'perfis' ou 'inventários 
pessoais' que então se tornam classes humanas. O s números são um resumo do que importa na intimidade, embora com a abstração das ciências ou do gerenciamento impessoal (H acking, 1995, p. 354). D uas classes de pessoas que $\mathrm{H}$ acking discute como inscritas nos números das estatísticas educacionais são os pais adolescentes e os pais ou crianças de risco. $\mathrm{H}$ acking nos permite pensar nas distinções além dos números e cuja categorização é imbuída de significações sociais que podemos aproximar do nosso interesse pelo conhecimento, a governança e a inclusão/ exclusão.

Se considerarmos, por um momento, a classe de pessoas que são os pais adolescentes (deixando a discussão sobre a noção de de risco para depois), a classificação é determinada. Ela tem uma cronológica, fisiológica e legal sucinta cláusula e trata-se de uma classificação que pode ser aplicada a muitas culturas - a classe é uma mulher, adolescente, grávida e (premissa não estipulada) solteira.

Recorrer a categorias de tipos de classes humanas é uma estratégia de administração social que transmite uma esperança de que as classes de pessoas e seu comportamento possam caber em leis práticas que permitam a administração social das classes humanas usando, por exemplo, leis para mudar as condições presentes do genitor adolescente (single parent) e das crianças de risco, digamos, e predizer o que se seguirá. O s tipos de dasses humanas são ostensivamente empregados em práticas de reformas para exprimir um esforço humanitário que visa a providenciar recursos para escolas que têm constantemente fracassado em suas metas sociais e éticas. Portanto, queremos a classificação certa e a distribuição correta de modo a que os males possam ser enfrentados mediante um curso de ação que os mudará para melhor e impedirá que outros a eles se acrescentem (H acking, 1995, p. 360). Pode-se claramente identificar os conjuntos de relações e a causação prática nos relatórios estatísticos como uma forma dessas leis práticas: os princípios dos números devem ser conhecidos para que possamos interferir, intervir, ajudar e melhorar.

A classificação em tipos de classes humanas funciona como uma idéia sem conhecimento. Com isso, queremos dizer que se trata de uma categoria mobilizada com um certo tipo de perícia em que a classificação é interpretada. Para considerar essa possibilidade, precisamos lembrar que a relevância de genitor adolescente enquanto tipo de classe humana foi construída historicamente e não é natural. ${ }^{12}$ Embora inteiramente fundamentada por sua natureza, genitor adolescente é uma categoria que surge para descrever al go problemático e, de algum modo, 
considerado como um desvio. M as a categoria também cria uma classe humana que se mobiliza sob a ação de peritos que determinam e transformam um conhecimento num contexto social particular ( $\mathrm{H}$ acking, 1995, p. 356). G enitor adolescente foi uma palavra que surgiu nos subúrbios americanos brancos dos anos 60 , mas que conota a gestão precoce (early parenting) dos guetos urbanos negros dos anos 80 e 90 (ver Lesko, 1995). Recentemente, seu significado cultural mudou a tal ponto que um eufemismo foi introduzido por sociólogos: gestão precoce.

Esse novo modo de descrição tem por conseqüência a emergência de novas possibilidades de ação. Enquanto projeto de ciência social, genitor adolescente é uma categoria que possibilita que pessoas sejam cuidadas e orquestradas, como argumenta H acking (1995), por uma equipe de peritos. D edicam-se a ela programas de pesquisa, pode-se prever futuros desvios e ela tem um crescimento que pode explicá-la, ordená-la, determinar suas conseqüências e anulá-las. O s tipos de classes humanas descritos formam as bases do relatório estatístico. 0 genitor adolescente, os desempregados, 0 abandono escolar, a etnicidade, 0 gênero, ou os nascidos no exterior das tabelas estatísticas são associados a significados sociais e, portanto, a uma peculiaridade e diferenciação numa sociedade. As classes de pessoas que são os pais adolescentes, étni cos, nascidos no exterior, abandono escolar têm conseqüências, uma vez que programas são criados para eles, discursos inventados para descrevê-los e criar planos para eles, a fim de anular as classes de pessoas descritas.

Ao examinarmos mais profundamente as construções de classes humanas, as distinções integram uma relação particular e peculiar de governo e de inclusão/exclusão sociais. Pelo menos desde o século XIX, as classes humanas vêm sendo construídas por meio da ciência da normalidade e do desvio. 0 s tipos de classes humanas descrevem, em parte, como a classe difere do usual e avaliam, em parte, no que difere do que é certo e normal. Certas classes de pessoas são determinadas como diferentes ou em desvio das normas - da criança normal, das idiossincrasias normais, do discurso normal, do desenvolvimento normal (H acking, 1995, p. 371). Além do mais, as categorias de normalidade e desvio de classes humanas são uma classe administrativa para distinguir, enumerar, controlar e melhorar os que desviam em relação a imperativos burocráticos. ${ }^{13}$

0 paradoxo de se fabricar classes humanas é que cada distinção de desvio é uma normalização e divisão que deixa esse tipo de classe humana fora das regras e normas de própria razão. Tomemos as categorias tipicamente empregadas nas estatísticas e na política educacional para 
resolver os problemas de inclusão e exclusão, como desemprego, minoria, classe, educação especial, abandono escolar, parente de risco ou adolescente. Cada uma dessas categorias pressupõe um conjunto particular de normalidade: 0 desempregado pressupõe uma norma de emprego; as minorias pressupõem uma norma de maioria universalizada, embora não explicitada; classe pressupõe geralmente trabalhadora ou 'inferior' que é justaposto implicitamente com as normas do que não é mencionado, mas pressuposto como não sendo classe trabalhadora ou 'inferior'. A criança, os pais e grupos culturais (etnicidade, minorias) são pressupostos como diferentes de algumas outras crianças que não são mencionadas, mas têm uma presença silenciosa na organização das categorias de comparações. As palavras integram uma codificação de normas de um estado de coisas médio ou normal segundo o qual toda criança deve ser entendida e avaliada. A inscrição de normalidade e as divisões não são intencionais por parte dos elaboradores de políticas ou da pesquisa social, mas estão integrados no sistema de razão na medida em que classifica, diferencia e divide. Q uer gostemos ou não, nossos sistemas de discursos integram divisões, normas e valores de distinções.

I sto nos leva a considerar que as classificações e divisões não evoluem num campo igualitário. O s padrões discursivos geram princípios que qualificam e desqualificam indivíduos quanto à sua participação e ação.

\subsection{Biografias que governam a inclusão ea exclusão}

A construção de classes de pessoas produz uma biografia para o indivíduo. ${ }^{14} \mathrm{O}$ indivíduo é definido de maneira normativa em relação a agregados estatísticos a partir dos quais características específicas podem ser atribuídas a essa pessoa e segundo as quais seu crescimento e desenvolvimento podem ser monitorados e supervisionados. As características do indivíduo são organizadas de modo "transistórico", o desenvolvimento específico à idade é separado de qualquer situação histórica imediata. Ao aplicar um cálculo de probabilidade, o raciocínio estatístico constrói nossa compreensão de como as crianças aprendem, da realização escolar e dos atributos sociais e psicológicos presumidos como causa de fracassos escolares e da relação dos indivíduos ao progresso social e econômico.

As biografias que elaboram classes de pessoas têm implicações no governo da inclusão/exclusão sociais. As estatísticas acarretam uma maneira de condensar ou reduzir indivíduos na forma de 'perfis' ou 'inventários 
pessoais' que são então resumidos para formar 'perfis' ou 'inventários pessoais de classes humanas organizadas em práticas institucionais. ${ }^{15} \mathrm{~A}$ proliferação de programas educacionais ligados a classes humanas em escolas bem como as formulações de novas especialidades nas escolas (psicólogos escola, assistentes sociais escolares, diferenciações em professores de educação especial) são exemplos de como as categorizações não 'constróem' a individualidade.

Lesko (1995) enfatizou como a categoria 'genitor adolescente' produz biografias que relacionam raça, classe e gênero num esquema interpretativo para ordenar práticas sociais. Ela argumenta que a categoria de 'mães em idade escolar' constrói, nos EU A, uma interpretação de necessidade por meio de debates culturais e políticos a respeito da moralidade americana e dos valores familiares. 0 genitor adolescente é organizado em programas nos quais o comportamento individual é definido como patológico mediante um encadeamento de relações acima chamado de causalidade prática. Os debates culturais sobre a deterioração, a permissividade e a dependência da família tornam-se erros individuais ligados a valores nocivos, ao desespero e à falta de futuro.

O s sistemas de classificação são uma prática cultural que estrutura o campo de ação possível. Isso acontece porque as condutas se tornam calculáveis pela inscrição dos princípios de desempenho e dos modos de subjetivação, isto é, das regras por meio das quais os indivíduos se comportam como pessoas responsáveis, competentes e que motivam a si mesmas (D ean, 1995). N a pesquisa EGSIE, há fortes evidências de que as distinções das estatísticas nacionais e internacionais são integradas e ajudam a constituir a maneira como sistemas educacionais, professores e atores políticos 'raciocinam' a respeito da política e da governança de inovação, em que se deve enfrentar os problemas de inclusão e exclusão. N o contexto sueco, os relatórios governamentais têm categorias de mau desempenho educacional, como 'não passou em todas as matérias' e alunos com 'Background Estrangeiro'. Baseados na identificação de alunos que fracassam, programas institucionais são introduzidos para remediar os problemas das crianças que cabem nessas duas categorias de modo a que possam completar as séries. As categorias estatísticas pressionam os indivíduos com uma identidade calculável por meio da qual os peritos agem e os indivíduos devem encarar a construção de sua própria participação e identidade. A construção de distinções se torna tão embutida na ordem das coisas que preside também à resolução de problemas à medida que peritos pensam e repensam a classificação de causalidade. 
N esse contexto de governo, o aumento de distinções estatísticas nos relatórios educacionais nacionais e internacionais é expressivo na construção de novas biografias para o problema da inclusão/exclusão sociais, mas de uma maneira tomada em consideração nas formulações de políticas. Q uando se examina os relatórios nacionais e internacionais atuais sobre estatísticas, por exemplo, constata-se um aumento tremendo nas categorias que são utilizadas para descrever e relacionar os inputs e outputs dos sistemas educacionais. A formulação estatística da U nesco, por exemplo, dos padrões internacionais de classificação de educação, substituiu, em 1998, categorias institucionais por classificações de programas educacionais. Isto foi feito para que os planejadores educacionais pudessem relacionar mais facilmente diferentes ocupações a diferentes tipos de níveis de educação e campos de estudo. Vários níveis educacionais da pré-escola até a educação superior foram construídos para calcular a movimentação pelo sistema escolar e os pontos onde as exclusões ocorriam. 0 aumento de distinções incluiu uma nova taxinomia internacional que pretende classificar programas e recursos especiais em três subcategorias diferentes de educação especial, abrangendo desde os incapacitados (cegos e com problemas de visão) até os que sofrem de dificuldades de aprendizagem sem razão clara e as desvantagens produzidas por fatores essencialmente socioeconômicos, culturais e/ou lingüísticos. 0 relatório atual sobre educação mundial traz um apêndice de onze tabelas de indicadores estatísticos 'que dizem respeito a aspectos selecionados de educação e ao cenário demográfico, socioeconômico, cultural e de comunicação' (p. 115). ${ }^{16}$

As distinções e divisões das estatísticas que relacionam a criança, o lar e a escola são sistemas de normalidade e desvio. Sua importância consiste em inscrever uma biografia da criança por meio das qualidades cal culáveis do indivíduo que são designadas como diferentes das de outros. A distinção é visualizada nas distinções numéricas mais do que como divisão aberta de categoria (como garantir que o mesmo número de moças e moços tenha aula de matemática). Portanto, torna-se possível focalizar os grupos excluídos nas categorias e inscrever, ao mesmo tempo, sistemas de exclusão.

Aqui, podemos considerar um novo tipo de classificação nas estatísticas nacionais e internacionais, a classe de pessoas minoritárias. A classe humana minoria é uma categoria visando a focalizar grupos para ajudar a estabelecer um sistema social mais justo e eqüitativo. Ela cria uma biografia que relaciona questões econômicas de emprego a questões psicológicas (amor-próprio), educação (níveis de realização e abandono 
escolar). Podemos também pensar que boa parte da discussão atual sobre diversidade e multiculturalismo está ligada a classes de pessoas estabelecidas por meio de categorias de minoria construídas mediante discursos formados politicamente e preocupados com questões de governança.

Entretanto, minoria é um conceito popular importado pela teoria e pelas estatísticas (Bourdieu \& Wacquant, 1999). Segundo a ordenação das pessoas, todo indivíduo pode encaixar-se num conjunto de categorias que 0 defina como uma minoria. N os EUA, por exemplo, descendentes de puritanos ou aristocrata inglês são 'minorias,' mas as políticas de categorias focalizam apenas grupos cujas características populacionais exprimam um desvio de algum valor de normalidade tácito. Estão presentes normas do futuro a partir das quais progresso e melhoria podem ser obtidos. As minorias estatísticas produzem uma figura compósita de perfeição rumo à qual as crianças podem progredir. As categorias não se limitam à política do Estado, mas são frequentemente consideradas como 'reais' pelos projetos políticos de quem é classificado como minoria. Em muitos programas de formação dos professores nos EU A, as categorias de minorias são traduzidas em categorias de diversidade, uma vez que professores preservice são mandados para 'áreas focalizadas' para entender as biografias de alunos classificados como diversos e minoria. Contudo, as biografias integram superposições de classes biológicas, médicas, sociais, culturais e administrativas que são transformadas num todo contínuo para construir as crianças 'diversas' ou em minoria. ${ }^{17}$

Todavia, a construção de biografias não ocorre apenas com crianças na escola, mas também com os professores que são construídos como portadores de luz para lugares escuros bem como fatores de produção custosos em orçamentos limitados. Existem cálculos que ordenam um campo de profissionalização cujas estatísticas e categorização devem ser relacionadas de volta aos indicadores de sistema de inclusão e exclusão, como o número de professores qualificados, de professores de educação especial (número de professores de educação especial para resgatar os alunos), o tamanho das classes, o status dos professores e as escolas particulares ou reservadas a uma elite especial. N os relatórios há comparações a respeito da disponibilidade de livros escolares, de lousas que podem ser usadas nas salas de aula e de postos de professores, bem como das proporções alunos/professores. Q uanto à qualidade do ensino e às proporções alunos/professores, o relatório Education at a glance (1998) afirma:

Embora asescolas demuitos países estejam usando mais computadoreseoutras tecnologias educacionais, os professores continuam sendo o recurso mais 
importantena instrução do aluno. A proporção entreal unosepessoal docente é portanto um indicador importante dos recursos que os países dedicam à educação. Em razão da dificuldade de se obter medições diretas da qual idade do ensino, os indicadores sobre a quantidade de inputs escolares são freqüentementeutilizados como procurações paramedir a qual idadedo ensino. (p. 140)

Podemos apreciar essa afirmação à luz dos estudos sobre capital cultural e escolaridade (Bourdieu, 1989/1996), sobre educação progressiva e gêneros (Wakerdine, 1990) e sobre estrutura de classes na educação urbana (M iron, 1996) para considerar os modos em que as questões de qualidade não são meramente uma busca 'objetiva' de um critério definitivo de verdade e de bem, mas um conceito onde se entrelaçam considerações sociais, morais e políticas. Pensar nas categorias de professor e de qualidade do ensino é entrar numa teia que confere inteligibilidade às biografias de escolaridade. 0 professor deve construir sua realidade através dos sistemas de categorias inscritos.

\subsection{Eqüidade como uma problemática: Separar a exclusão da inclusão}

$\mathrm{N}$ as estatísticas nacionais e internacionais há um movimento que vai de uma governança por regras que enfatiza uma abordagem input (como os inputs de classes sociais se relacionam com os outputs - matrículas ou realização ou o dinheiro gasto em sistemas educacionais nacionais) rumo a uma governança de educação enquanto abordagem output por objetivos e avaliações em que os resultados da educação são real çados. 0 desenvolvimento e uso do TIM SS (T hird International M athematics and Science Study [Terceiro Estudo Internacional sobre M atemática e Ciências]) são um bom exemplo, aqui, uma vez que seus testes de matemática e de ciência criam discursos internacionais sobre a educação centrados em resultados e comparativos (ver, por ex., Education at a glance, 1998, p. 309-321). Essa mudança pode estar relacionada a outras mudanças nas relações organizacionais de práticas de governo de educação centralizadas ou decentralizadas (ver, por ex., Lindblad \& Kallos, 1994; Popkewitz, 1996).

Essa mudança se limita às práticas organizacionais: as regras de prática de governo embutidas na ordenação e na divisão de números de práticas não têm mudado. A razão estatística integra um modo particular de pensar, 'ver' e agir em política e na pesquisa em ciências sociais que temos chamado, em outro lugar, de 'a problemática da eqüidade' 
(Popkewitz \& Lindblad, 2000). Esta problemática dá atenção à representação, ao acesso e à exclusão de indivíduos e grupos de práticas educacionais e sociais. Encontra-se tanto na pesquisa qualitativa como quantitativa. 0 interesse se concentra sobre como políticas focalizaram grupos de atores sociais definidos como excluídos, tais como os definidos por classe social, gênero, raça ou etnicidade. N esta problemática, os relatórios estatísticos nacionais buscam desenvolver programas que diminuam as grandezas de certas características específicas de populações para produzir sua inclusão.

Um pressuposto maior da problemática da eqüidade é 0 acesso e a representação. Os números de inclusão e exclusão são um dispositivo de inscrição que torna os campos de governo representáveis e adequados para cálculos e deliberações. Renda e economia formam, textualmente, um conjunto de categorias que devem ser governadas para criar uma eqüidade maior. As categorias de exclusão são estatísticas que fornecem números sobre famílias de desempregados, famílias pobres, saúde ("mães solteiras", "nascimentos com baixo peso") ligados à educação (realização, exclusão do ensino médio), estabilidade social (ambientefamiliar, divórcio, divórcio em que o marido não é qualificado), mães adolescentes, criminais (delinqüência juvenil) (ver as discussões do U.K. Roundtree Report, por ex., em Alexiadou, no prelo, e Alexiadou, Lawn, \& O zga, no prelo). As quantidades representadas nas categorias estatísticas são relacionadas pelo cálculo da orientação legislativa por meio da política fiscal, da legislação e das práticas burocráticas.

A problemática da eqüidade determina um campo de práticas culturais em que a inclusão emerge como distinta da exclusão; pressupõese que decretar as políticas corretas eliminaria a exclusão e criaria uma sociedade eqüitativa. As regras de razão são que a administração social adequada e a coordenação das quantidades que exprimem as categorias vão governar as classes de pessoas relevantes e, assim, produzir a inclusão e eliminar a exclusão. Embora seja um elemento importante das políticas sociais preocupadas com as questões de eqüidade, a problemática da eqüidade também obscurece de que maneira os sistemas de inclusões são ao mesmo tempo sistemas de exclusão. Esse é o fardo que os números carregam na política e pesquisa sociais. As fabricações de classes de pessoas constróem, normalizam e dividem pessoas, de modo a distinguir as características de normalidade do que está fora delas. 
4. D erisco: razão, estatísticas e relação entre conhecimento, governo e inclusão/exclusão

U ma categoria importante nas estatísticas que relacionam a governança de educação com a inclusão e a exclusão é a de risco. D e risco é uma expressão que apareceu na educação nos anos 70, como uma maneira de descrever alunos que não tinham realização escolar e de organizar projetos capazes de trazer o progresso social. É uma categoria ao mesmo tempo descritiva e avaliatória, uma vez que está em relação com a problemática da eqüidade. Pressupõe-se, como para as outras políticas de inclusão social, que a administração social adequada e a coordenação de práticas governarão as classes de pessoas relevantes para, com isso, obter a inclusão e eliminar a exclusão. Acadêmicos, burocracias e grupos comunitários fizeram de "de risco" uma noção que prescreveria medidas para promover uma sociedade mais inclusiva por meio da escolaridade. Sua integração nas políticas e pesqui sas sociais foi um esforço consciente para substituir, nas literaturas britânica e norte-americana, rótulos criticados por colocarem a culpa nas vítimas, como os de "culturalmente desfavorecido" ou "socialmente desfavorecido". A vantagem da expressão "de risco" é que parece ser um termo neutro, não associado às dificuldades políticas e ideológicas das tentativas anteriores de classificar alunos que sofreram econômica, social e "educacionalmente". M as uma pressuposição de "de risco" é que classificar crianças e famílias de risco é uma tecnologia de governança. Risco é "primeiro um esquema de racionalidade, uma maneira de desfazer, rearranjar e ordenar certos elementos da realidade" (Ewald, 1991). É uma categoria que representa um sistema complexo de idéias que, num sentido kantiano, não se referem a qualquer realidade específica. E uma categoria que fabrica: é uma ficção e ela constrói classes de indivíduos.

A noção de risco e de 'de risco' permeia a literatura das ciências e das políticas sociais, bem como as classificações mediante as quais o desvio e a normalidade são fabricados na escolaridade. Q uando ol hamos para as estatísticas nacionais e internacionais, certos indicadores de crianças 'de risco' são utilizados para falar de inclusão e exclusão. As estatísticas, por exemplo, recorrem à categoria de 'de risco' para diferenciar grupos populacionais que são excluídos: a categoria de risco fornece uma classificaçãao de crianças de minoria étnica que são classificadas como categoria de alto risco, "uma vez que $16 \%$ das crianças permanentemente excluídas a ela pertencem, sendo quase metade da categoria de alto risco composta por afro-caribenhos, embora representem apenas 1\% da 
população" (Alexiadou, Lawn \& O zga, no prelo). As estatísticas vinculam diferentes categorias de números: faltar às aulas, exclusão escolar e crime e alunos com necessidades educacionais especiais, particularmente crianças afro-caribenhas ou confiadas à assistência pública.

Se aplicarmos um cálculo de probabilidade, risco é uma característica da população que descreve, que elabora classes de pessoas - os afrocaribenhos vinculados a categorias de desvio: crime, necessidades educacionais especiais e faltar às aulas, entre outros. Todo indivíduo nessa classe de pessoas está sobre as mesmas bases; 0 grupo 'de risco' compreende uma população em que pessoas e acontecimentos podem ser considerados como fatores de risco. Todo mundo é potencialmente de risco e precisa de supervisão e regulação, tornando assim possível um fenômeno norteamericano de criação de perfis raciais, por exemplo. $N$ inguém foge "propriamente" dessa característica. Seu esquema organizador de gerenciamento e de racionalidade pode ser realizado em toda e qualquer instituição. Pode ser aplicada a qualquer um, em função de como os perigos são analisados e os acontecimentos considerados (Ewald, 1991; D efert, 1991). A "individualidade" não está mais correlacionada a normas abstratas ou a um sujeito responsável. Antes, a individualidade está ligada a outros membros da população "de risco".

Risco, enquanto categoria estatística, é 'maior' do que as grandezas que exprime. Integra um conjunto de regras de razão e classificações que exprimem historicamente diferenças de posição e interesses sociais. É uma razão a respeito de populações que apareceram em meados do século XIX, quando um psiquiatra francês tentou fazer com que as autoridades públicas empreendessem uma monitoração especial daquelas "populações de risco desfavorecidas." As primeiras pessoas a serem tratadas dessa manei ra sofriam de doenças mentais ou de anormalidades ligadas à qualidade de suas condições de vida - desnutrição, alcoolismo ou promiscuidade sexual. Algumas correlações estatísticas foram encontradas entre séries de fenômenos. Argumentando em termos de risco objetivo, o psiquiatra sugeriu às autoridades públicas que uma monitoração especial desses grupos de população promoveria a higiene mental (Castel, 1991, p. 284-286).

Q uando adotadas pela política social e pelas práticas profissionais de escolaridade, as tecnologias de "risco" introduziram questões de governabilidade que transformaram crianças e famílias em entes socialmente perigosos. Q uando se trata de indivíduos como membros de uma população "de risco," por exemplo, o objetivo é geralmente antecipar e impedir um acontecimento indesejável, como o alcoolismo ou o fracasso escolar. $O s$ atos individuais são menos importantes que a combinação de fatores 
de "risco" que define uma população como um todo. Contemplam-se "fatores, correlações estatísticas de el ementos heterogêneos" (C astel, 1991, p. 288). C astel (1991) afirmou: "Estamos numa perspetiva de gerenciamento autonomizado de populações conduzido na base de perfis diferenciais daquelas populações estabelecidos mediante diagnósticos médicopsicológicos que funcionam como perícias puras" (p. 291).

Contudo, a dlasse de pessoasilustrada ao se classificar uma população de risco não é apenas uma de governo de pessoas. É interativo na medida em que é trazido de volta ao individual para criar biografias individuais pela definição do indivíduo como membro de um campo de população para monitorar e impedir manifestações de comportamentos de "risco".

Risco ilustra uma "dupla hermenêutica." Risco integra um modo de classificar pessoas por meio do raciocínio populacional. N ão é apenas uma maneira de ordenar pessoas, pois integra também a capacidade de mudar como as pessoas se pensam enquanto atores no mundo. À medida que os indivíduos começam a ver suas vidas pessoais em relação a uma trajetória fornecida pelas tabelas de mortal idade das companhias de seguro, o tempo não se limita mais ao espaço de vida nem às interações do indivíduo.*

\section{Construir 0 outro}

O s números são uma característica essencial do novo conhecimento positivo da economia política, da sociologia, da saúde pública, da medicina, da psicologia e assim por diante. N úmeros conferem certeza aos modos em que se espera que as pessoas apliquem e se beneficiem da ciência e do conhecimento técnico. 0 que está em fluxo se torna estabilizado de modo a parecer apenas como problema técnico restrito a um campo de objetividade. O s números outorgam uma certeza e uma qualidade conclusiva que são técnicas por um lado, embora participem da fabricação de 'classes de pessoas' dentro das quais pensamento e ação podem ocorrer.

É por considerar os números como fabricações mais do que como uma 'ferramenta' para implementar o governo de uma educação e sociedade mais ou menos inclusivas que conseguimos focalizar as estatísticas como uma prática de governo através de suas regras de razão. Argumentamos que os números não existem meramente como entidades lógicas, mas se sobrepõem a outros discursos para conferir inteligibilidade a práticas de cultura. O s números se sobrepõem a discursos sociais, culturais, econômicos e administrativos para formar um plano único que permite calcular classes de pessoas. Investigamos como um sistema de 
razão subjacente à problemática da eqüidadee às crianças 'de risco' confere inteligibilidade aos fenômenos de escolaridade e às crianças. 0 mais expressivo não foram osnúmeros per se, mas a maneira como estão inscritos numa teia a partir da qual normalidade e desvio são fabricados. 0 s números em relatórios nacionais e internacionais, então, não descrevem meramente realidades preexistentes nem constituem realidades apenas por meio de sua lógica. Eles as constituem pelas maneiras como os objetos do mundo são ordenados e divididos.

0 conhecimento enquanto prática de governo que inscreve distinções e divisões (classes de pessoas) oferece uma maneira de entender as relações entre educação, governança e inclusão e exclusão. A importância da quantificação numérica não é que os números existam ou que sejam bons ou ruins, mas que os sistemas inscritos de razão normalizam a criança, a família e a comunidade. A governança, argumentamos, está nos procedimentos de ordenação por meio dos quais o pensamento foi disciplinado pelas distinções e divisões que circulavam nas estatísticas educacionais. O s princípios de raciocínio discriminam, distinguem e normalizam o que a criança é e deve se tornar. Inclusão e exclusão não são distintas, mas mutuamente constituídas, uma vez que as distinções e diferenças inscrevem limites e divisões entre o normal e o que está fora dele. Além do mais, o campo das práticas culturais onde os números são inscritos envolvia uma causalidade prática na qual biografias foram produzidas a respeito das habilidades e capacidades de certas crianças que não "cabem" nas normas da média - as crianças 'de risco'.

0 governo da razão das estatísticas gerencia por meio de uma relação dupla. As comparações na educação que ordenam a competição entre nações, regiões e empresas são também fatos sociais que constróem diferenciações entre os que contribuem com a sociedade - aqueles que devem ser incluídos como membros produtivos da sociedade - enquanto os membros não produtivos são divididos (Lindblad, 2000). Ao mesmo tempo em que o uso de estatísticas é uma maneira de construir classes humanas para abrir possibilidades para o futuro, é também um modo para que a individualidade seja descrita de novo e que as pessoas possam experimentar a si mesmas. C omo sugeriu $\mathrm{H}$ acking, "C riar novas maneiras de classificar as pessoas é também mudar o que podemos pensar de nós mesmos, mudar nosso sentido de valor próprio e até nossa maneira de nos lembrar do nosso próprio passado" (H acking, 1995, p. 369).

Ao focalizar as estatísticas como discursos sobrepostos, buscamos nos afastar de boa parte das discussões em teoria social que são dominadas por teorias de 'rotulagem'. Essas teorias enfocam o indivíduo institu- 
cionalmente confirmado pelo rótulo e levam as pessoas a adotar padrões estereotipados de comportamento - a 'profecia de realização própria' ou efeito Pigmalião que circula pela educação, psicologia e sociologia para discutir como os modos de pensamento a respeito das categorias de política e ciência sociais produzem identidades que circulam com as crianças enquanto profecias de "realização própria".

N ossa abordagem do pensamento das estatísticas havia de considerar os cálculos dos excluídos como se sobrepondo a outros discursos dos campos econômicos, sociais e culturais para formar as biografias de classes de pessoas - baixa realização, pobreza, etnicidade e assim por diante - que tornam categorias e números expressivos enquanto práticas de governo. Por proceder deste modo, conseguimos desmantelar as divisões entre qualitativo e quantitativo no entendimento das fabricações inerentes às discussões contemporâneas sobre pesquisas educacionais.

N ossa análise também questionou o modo como as discussões contemporâneas de política têm privilegiado imperativos econômicos ao dirigir as mudanças na escolaridade. D e certos discursos liberais e neoliberais depreende-se a linguagem de políticas orientadas para o mercado, em que a escolha de uma escola, cupons e privatização estão associados. $\mathrm{N}$ osso projeto de pesquisa européia bem como as análises acima sugerem que os discursos do neoliberalismo (e suas metáforas aparentemente econômicas) formam, na realidade, uma teia de discursos múltiplos que vêm junto e dizem respeito a campos culturais de produção e de reprodução. Pressupor que as categorias do neoliberalismo não passam de uma linguagem econômica obscurece a superposição dos discursos e as regras de razão produzidas nas práticas de política atuais (ver Popkewitz, 2000). 0 uso de um termo aparentemente econômico, como pobreza, inscreve representações políticas e culturais, uma vez que está vinculado a outros termos, como desenvolvimento sustentável e paz no texto.

U ma nota final a respeito de política, governança, inclusão e exclusão. Q uando falamos nas discussões atuais a respeito do assim chamado 'encolhimento do Estado' que foi a marca registrada das políticas neoliberais e do Terceiro Caminho de modo a encontrar uma nova relação entre políticas de bem-estar social e reestruturação econômica do Estado, o foco recai sobre uma sociologia de instituições e organização. Contudo, quando examinamos os sistemas de razão que temos discutido em relação aos relatórios estatísticos, não há esse encolhimento de governo, apenas mutações. Existem cada vez mais distinções nacionais e internacionais mais sutis e uma elaboração de estatísticas de política. Assim, podemos chegar a uma conclusão contrária à intuição em relação ao problema de 
governança. Se pensarmos nas estatísticas como integrando a idéia de administração social, houve um crescimento dramático de governança por meio da elaboração de distinções mais sutis das classes de pessoas governadas.

Recebido para publicação em abril de 2001.

\section{$\mathrm{N}$ otas}

1. O projeto abrangia a Finlândia, a Alemanha, a G récia, a Grã-Bretanha (Inglaterra e Escócia), a I slândia, a Espanha e a Suécia. Pesquisadores da Austrália estão participando deste estudo. 0 EGSIE foi desenvolvido com o apoio da Comissão Européia, D G XII.

2. Esses serão incluídos nos estudos de casos individuais do projeto que serão entregue em janeiro de 2001.

3. Existem muitos problemas de "validade", aqui, quando se considera o caráter construído das categorias e a operações por meio das quais os casos são classificados. Entretanto, essas questões não são tratadas neste texto.

4. Ao reconhecer as funções práticas das estatísticas para a política do Estado e as ciências sociais, o pensamento estatístico sofreu mudanças influenciadas por várias teorias, desde o determinismo enquanto princípio diretor nos séculos XVIII e XIX (leis determinadas, válidas e universais do fenômeno a ser decifrado) até a erosão do determinismo quando as contingências do acaso foram contidas por meio do pensamento estatístico e dos métodos estatísticos estocásticos (uma amostra representativa substitui normas típicas e estatisticamente derivadas e os desvios são utilizados para estabelecer padrões de julgamento). Como sugere Kalpagam (2000), a fé na possibilidade de predição foi erodida pela indeterminabilidade caótica e os sistemas dinâmicos não-lineares, os quais ameaçaram a teoria dos sistemas e conferiram maior importância a determinismos locais, um tema que tem ecos relacionados aos discursos políticos sobre controle local, individualidade e comunidade.

5. Esses indicadores costumam aparecer nos relatórios nacionais dos EU A sobre o progresso no sucesso em matemática e ciência (tal como nos estudos TIM S) ou nas discussões sobre estudos das matérias escolares, das percentagens dos que abandonaram a escola (dropouts) etc.

6. Recorremos à noção de 'lógica prática' para examinar como as relações textuais das categorias por meio das quais os dados são coletados nos relatórios formam uma maneira de se entender relações, resultados, e relações de causa e efeito. Essa causação prática tem mais a ver com a gramática do texto do que com as teorias estatísticas. A construção de uma lógica prática e a causação serão discutidas mais adiante neste artigo.

7. Para alguém treinado em lógica formal, o que é paralelo não pode formar uma teia de superposições. Entretanto, a prática da lógica é diferente da lógica da prática. Pensamos a escola moderna e os diferentes discursos como caminhando em linhas paralelas que, em dados momentos históricos, se juntam para formar um modo de conferir inteligibilidade aos objetos do mundo social e aos nossos 'selfśs naquele mundo. A escola moderna e seu currículo podem ser entendidos como um movimento de idéias a respeito de salvação, infância, racionalidades políticas do cidadão, bem como mudanças tecnológicas e arquiteturais que vêm juntas no que agora chamamos de escola moderna.

8. N ossa intenção não é de estabelecer uma relação causal entre órgãos internacionais e relatórios nacionais, uma vez que existe uma mutualidade, já que certas nações conseguem estabelecer sua categorias de medições como universais. Ver Bourdieu \& Wacquant, 1999. 
9. O Staatenkunde, o estudo sistemático de Estados, uma forma primitiva do que chamaríamos de política comparativa, surgiu no Censo M unicipal de N uremberg, em 1449 (Alonso \& Starr, 1987, p.13). A tradição Inglesa de aritmética política foi a aplicação do cálculo racional ao entendimento, exercício, e melhora do poder do Estado. No século XVIII, serviria a reverter o crescimento do Estado. As sociedades estatísticas do século XIX deviam coletar fatos objetivos, principalmente numéricos, mas ainda dados que hoje chamaríamos de 'qualitativos.'

10. Referimo-nos novamente à Tabela 1 com as categorizações nela realizadas, onde 0 ensino médio inferior consta como baixo êxito escolar relacionado ao desemprego. A categoria 'ensino médio inferior' pode ser considerada como o resultado de práticas discursivas de longa duração tanto quanto a construção da distinção de pessoas 'desempregadas'. A combinação dessas duas distinções constitui um tipo especial de pessoas 'desempregados com educação inferior à de outros', comparadas a pessoas empregadas com educação 'mais alta'. 0 s 'outros' são identificados 'com uma biografia e enquanto sujeitos para medidas diferentes por parte do estado'. Talvez mais educação?

11. Essa comunidade é um fenômeno recente, produzido à medida que agências internacionais e interestaduais trabalham com categorias comuns por meio das quais comparam nações. Essa comunidade das categorias estatísticas não é uma simples globalização fundada, por exemplo, por esforços da Comunidade Européia para desenvolver uma identidade por meio de projetos educacionais ( $N$ óvoa, 2000), mas também por debates políticos nacionais nos quais, no caso dessa discussão, a educação se tornou uma medida de modernização para o consumo nacional.

12. H acking (1995) chama nossa atenção para diferenças entre coisas da 'natureza', como os quarks e os tripeptídeos, e das classes humanas, como gravidez adolescente e adolescência. Ao se comparar coisas como camelos ou micróbios, suas ações independem de suas descrições, o que não é o caso com as classes humanas.

13. As categorias abandono escolar, minoria ou educação especial, esta uma categoria importante empregada em relação ao problema de inclusão social, são categorias administrativas. H acking (1995) sugere, por exemplo, que a categoria autismo ou incapacitado física ou emocionalmente são classes administrativas específicas. Elas não constituem rótulos de doenças específicas, mas um guarda-chuva para muitas delas.

14. Preferimos usar 'biografia' a roteiros ou narrativas para enfatizar como uma individualidade é produzida e circula pelos cenários institucionais. A biografia é freqüentemente aumentada por práticas qualitativas, como portfólios no novo currículo e padrões de formação do professor, e por discursos médicos como os discutidos junto às categorias de 'pais adolescentes' e crianças 'de risco'.

15. Como mais acima, estamos falando de um sistema de razão que atravessa as práticas educacionais e poderia, portanto, explorar também abordagens qualitativas recentes da medição de indivíduos em 'avaliações de portfólios.' Essas, como os números, fornecem inventários pessoais que permitem calcular as aptidões do indivíduo e, portanto, conhecêlas de modo a poder interferir, intervir, ajudar e melhorar.

16. A primeira tabela é construída a partir da população e do PN B com categorias como taxa de crescimento de população (média etária 1985-1995), proporção de dependência (população entre 0 e 14 anos mais população acima de 65 anos enquanto percentagem da população entre 15 e 64 anos), população urbana (como definida por critérios nacionais), expectativa de vida ao nascer (quantos anos se espera que um recém-nascido viva, em média), taxa de mortalidade infantil (o número de crianças que morrem antes de completar um ano por 1000 bebês nascidos vivos), e o PN B per capita (produto nacional bruto per capita em dólares americanos), crescimento anual médio do PN B, números baseados nos indicadores 1997 do D esenvolvimento M undial, do Banco M undial.

17. Trata-se também, contudo, de uma categoria de administração social que é recortada de dentro de um dado Estado-nação para identificar um reconhecimento cívico e político de 
grupos particulares baseado em traços culturais ou étnicos. Portanto, certos agrupamentos de pessoas são juntados enquanto classe humana de minorias e focalizados para a intervenção do Estado enquanto outros permanecem do lado de fora da classificação, mas não da classe humana. As classes de pessoas transformadas em minorias não podem pertencer à média e estão sempre colocadas fora da normalidade. M as existe ainda uma "deistoricização" do fenômeno de inclusão/exclusão quando este é integrado às estatísticas internacionais ou à teoria social. Cria-se uma falsa universalização, na medida em que a classe sai das fronteiras nacionais (Bourdieu \& Wacquant, 1999, p. 51). Assim, nos EUA e no Reino Unido, as categorias de minoria são regidas por distinções negros/brancos (essa última com as categorias de minoria de Indianos, N egros, Bengaleses e Paquistaneses), ao passo que na Suécia e em Portugal, essas distinções visando construir diferenças não funcionam historicamente.

\section{EduCATIONAL STATISTICS AS A SYSTEM OF REASON: Relations Of GOVERning edUCATION ANd SOCIAL INCLUSION AND EXCLUSION}

ABST RACT: Theessay proceeds by first examining theidea of international and national statistics as a field of cultural production and reproduction concerned with the social administration of the freedom of theindividual. This social administration has a double quality. It is to make the world intelligible and calculablefor policy and social intervention. But a different element of social element of administration also comesinto play. The social administration is to achieve immediate or future interventions in the lives of individual human beings, but also that the changes in the conditions of people will also produce changes in the kind of people that they are. In this later sense of social administration, international and national reports of educational statistics are examined as fabrications of kinds of people. Fabrication isto consider the knowledge of statisticsas a fiction in the sense of the categories that are not real but representations that are made-up to identify and order relations for social planning, as in the histories of the classifications such as employment/unemployment, 'at-risk', and ethnicity and minorities But the fabricationsalso make biographiesthat, related to individual actions and participation. The essay examines: (1) Contemporary arguments about statistics as a function of modern state problem solving. (2) Statistics is then considered historically as embodying particular rulesand standards of reason related to theStateadministration of populations in the name of freedom and liberty. This administration involves the "taming of chance by making objects of the world intelligible and calculable for policy. (3) The third section is concerned with how the categories and magnitudes of numbers construct a practical causality of deviancy related to kinds of people and the biographies that social planners are to act on. (4) Finally, the notion of at-risk found in recent policy and statistical reporting is explored as embodying a particular set of rules of reasoning to producebiographiesthat simultaneously excludeasthey include. Our task of inquiry is different: it is to examine the system of reason in which statistical discourses circulate and to make apparent the duality of the knowledge of education in governing social inclusion/exclusion. The rulesthat are used to widen inclusion are, at thesametime, rules of normalcy 
and divisions whose implications are to simultaneously construct systems that exclude as they include.

Key words: Systems of reason; Stati stics, Educational governing; Exclusion; Inclusion; Policy; Change

\section{Referências bibliográficas}

ALEXIADOU, N. Statistical indicators, UK (England). In: LINDBLAD, S. \& PopkEwItz, T. (eds.), Statistical data and inclusion e exclusion, Uppsala, Sweden: Uppsala Reports on Education. University of Uppsala. (In press).

ALEXIADOU, N., LAWN , M ., \& OZGA, J. Educational governance and scial integration/exclusion: The cases of Scotland and England within the UK. In: LINDBLAD, S. (ed.), Statistical data and inclusion and exclusion (Technical report submitted to Brussels and printed as U ppsala Department of Education Research Report series). Brussels: D epartment of Education. (In press).

ALONSO, W., \& STARR, P. (Eds.). The politics of numbers: For the national committee for research on the 1980 census. N ew York: Russell Sage Foundation, 1987.

AMERICAN Council on Education. To touch the future: Transforming the way teachers are taught; An action agenda for college and university presidents. Washington, DC: American Council on Education, 1999.

BAKER, B. Childhood-as-rescue in the emergence and spread of the US public school. In: Popkewitz , T. \& Brennan, M. (eds.), Foucault's challenge: Discourse, knowledge, and power in education. New York: Teachers College Press, 1998, p. 117-43.

BO U RDIEU, P. Social space and symbolic power. Sociological Theory $7 /$ 1,1989 , p. 14-25.

The state nobility: Elite schools in the field of power. Stanford, CA: Stanford University Press, 1989/1996.

Distinction: A social critique of the judgment of taste. Cambaridge, M A: H arvard University Press, 1979/1984.

.\& Wacquant, L. The cunning of imperialist reason. Theory, culture, and society. 16/1, 1999, p. 4-58. 
CAST EL, R. From dangerousness to risk. In: Burchell, G., Gordon, C. \& M ILleR, P. (eds.), The Foucault effect: Studies in governmentality. Chicago: University of Chicago Press, 1991, p. 281-298.

CASTILLO PÉREZ, P. Statistical indicators, Spain. In: LINDBLAD, S. \& PO PKEWITZ, T. (eds.), Statistical data and inclusion eexclusion. U ppsala, Sweden: Uppsala Reports on Education. University of Uppsala. (In press).

DEAN, M. Governing the unemployed self in an active society. Economy and Society 24/4, 1995, p. 559-83.

DEFERT, D. Popular life and insurance technology. In: BurCheLL, G., Gordon, C. \& MILler, P. (eds.), The Foucault effect: Studies in governmentality. Chicago: University of Chicago Press, 1991, p. 211-34.

DREYFUS, H. \& RABIN OW , P. M ichel Foucault: Beyond structuralism and hermeneutics. Chicago: University of Chicago Press, 1983.

EDU CATION at a glance. OECD indicators. Paris: OECD/C eri, 1998.

EDUCATION Policy Analysis. Paris: OECD/Ceri, 1998.

EWALD , F. Insurance and risk. In: BurChelL, G., Gordon, C.\& MILler, P. (eds.), The Foucault effect: Studies in governmentality. Chicago: University of Chicago Press, 1991, p. 197-210.

FO U CAU LT, M. The political technologies of theindividual. In: M ARTIN, L., Gutman, H. and Hutton, P. (eds.), Technologies of the self. Amherst: The University of M assachusetts Press, 1988, p. 145-62. . Governmentality. Ideology and Consciousness 6, 1979, p. 5-22.

HACKING, I. The looping effects of human kinds. In: SpERBER, D., Prem ACK, D . and Prem ACK, A. J. Causal cognition: A multidisciplinary debate. Oxford: Clarendon Press, 1995, p. 351-94.

. How should we do the history of statistics? In: BURCHELL, G., Gordon, C.\& MILler, P. (eds.), The Foucault Effect: Studies in Governmentality. Chicago: University of Chicago Press, 1991, p. 181-96.

. The taming of chance. Cambridge, M A: Cambridge University Press, 1990. 
KALPAGAM , U. The colonial state and statistical knowledge. History of the human sciences. 13/2, 2000, p. 37-55.

KARADJIIA, E. Statistical indicators referring to educational governance and social inclusion/exclusion (G reece). In: S. LINDBLAD, S. (ed.), Statistical data and inclusion and exclusion (Technical report submitted to Brussels and printed as U ppsala Department of Education Research Report series). Brussels: D epartment of Education. (In press).

LESK O , N . The "Leaky N eeds" of school-aged mothers: An examination of U.S. programs and policies. Curriculum Inquiry. 25/2, 1995, p. 177-205.

LIN D BLAD, S. Statistical indicators-Sweden. In: LINDBLAD, S. \& PopKEWITZ, T. (eds.), Statistical data, governance, and inclusion and exclusion (Technical report submitted to Brussels and printed as U ppsala D epartment of education Research Report series). Brussels: D epartment of Education, 2000.

On educational systems and social inclusion/exclusion as constructions in international statitistical information. In: LIN DBLAD, S. \& PopkeWITZ, T. (eds.), Statistical data and inclusion \& exclusion. Uppsala, Sweden: Uppsala Reports on Education. University of Uppsala. (In press).

. \& KALLOS, D. (eds.). N ew policy contexts for education: Sweden and United Kingdom. Umea, Sweden: Pedagogiska institutionen, U mea universitet, 1994.

LUNDAH L, L. Governance of education and its social consequences: Interviews with Swedish politicians and administrators. In: LIN D BLAD, S. \& PopkeWITZ, T. (eds.), Statistical data and inclusion \& exclusion. Uppsala, Sweden: Uppsala Reports on Education. University of Uppsala. (In press).

MIRON , L. The social construction of urban schooling: Situating the crisis. Cresshill, NJ: H ampton Press, 1996.

NATIONAL Commission on Teaching and America's Future. What matters most: Teaching for America's future. Washington, D C : N ational Commission on Teaching and America's Future, 1996.

NÓ VOA, A., ALVES, N., \& CAN ÁRIO. Social inclusion and exclusion in Portugal: A statistical approach. In: LINDBLAD, S. \& POPKEWITZ, 
T. (eds.), Statistical data and inclusion \& exclusion. Uppsala, Sweden: U ppsala Reports on Education. University of Uppsala. (In press).

POPKEWITZ, T. Reform as the social administration of the child: G lobalization of knowledge and power. In: BURbuLEs, N . \& TORRES, C. A. (eds.), Globalization and educational policy. N ew York: Routledge, 2000, p. 157-86.

Struggling for the soul: The politics of education and the construction of the teacher. N ew York: Teachers College Press, 1998.

Rethinking decentralization and the state/civil society distinctions: The state as a problematic of governing. Journal of Educational Policy 11/1, 1996, p. 27-51.

. \& Lindblad, S. Educational governance and social inclusion and exclusion: some conceptual difficulties and problematics in policy and research. Discourse 21/1, 2000, p. 5-54.

RIN NE, R., KIVIRAUM A, J., \& SIM OLA, H. Statistical indicators of social exclusion/inclusion in schooling (Finland). In: S. LINDBLAD, S. (ed.), Statistical data and inclusion and exclusion (Technical report submitted to Brussels and printed as U ppsala D epartment of Education Research Report series). Brussels: D epartment of Education. (In press).

ROSE, N. Powers of freedom: Reframing political thought. Cambridge, M A: C ambridge University Press, 1999.

STARR, P. The sociology of official statistics. In: Alonso, W. \& STARR, P. (eds.), The politics of numbers. For the national committee for research on the 1980 census. N ew York: Russell Sage Foundation, 1987.

UN ESC O. Unesco 1998 statistical yearbook. Paris: Unesco and Berman Press, 1998.

VERDERY, K. Whiter "nation" and "nationalism"? D aedalus, 122/3, 1993, p. 37-46.

W ALKERDINE, V. School girl fictions. London: Verso, 1990. 